NOTAS Y DISCUSIONES

\title{
Propiedad intelectual y conocimiento público: Derechos del investigador y del ciudadano sobre el copyright ${ }^{1}$
}

\author{
ROBERTO FELTRERO OREJA \\ Departamento de Lógica, Historia y Filosofía de la Ciencia. UNED
}

ReSUMEN. El concepto de propiedad intelectual está llamado a ser la clave que oriente el desarrollo de la sociedad de la información en el siglo XXI. Los principios éticos, morales y sociales que subyacen tanto al diseño de las arquitecturas primitivas de Internet como a las leyes vigentes sobre propiedad intelectual se fundamentan en la publicidad de la información como el requisito básico para el desarrollo de conocimientos culturales, técnicos y científicos. Sin embargo, las nuevas tecnologías de la información también proporcionan los medios para extender el control tecnológico de todos los usos, legítimos e ilegítimos, del material protegido con copyright. Se analizan nuevos modelos de copyright y se proponen las licencias libres como forma de protección activa por el propio autor de los usos legítimos de su trabajo cognitivo, especialmente si se trata de conocimiento científico o humanístico subvencionado públicamente.

\section{Introducción}

Desde los medios de comunicación se nos bombardea incesantemente con el concepto de propiedad intelectual y el grave per-
ABSTRACT. Intellectual property is meant to be the key concept to drive the development of information society in the 21st century. The ethical, moral and social principles underlying both early design of Internet architecture and intellectual property laws provide a framework to claim for the publicity of information as the main requirement for cultural, technical and scientific knowledge development. However, new information technologies allow copyright owners to extend their control of both legitimate uses and misuses of copyrighted material. New models of copyright licenses are analyzed and proposed to protect fair use of cognitive work, particularly public scientific and humanistic knowledge, to the extent decided by the author himself.

juicio económico que representa para los autores la copia ilegal y la copia privada. Desde que la copia y la distribución de todo tipo de información ha perdido su valor material gracias a la digitalización y 
a la transmisión en red, se ve amenazado el soporte material que justificaba una actividad económica asociada a la creación y difusión de parte del conocimiento científico, tecnológico, humanístico o artístico.

El citado bombardeo mediático obedece al intento de reforzar socialmente el concepto de copyright y con ello ayudar a promover la reforma de la legislación a él asociada. Se persiguen nuevos marcos legales que autoricen mecanismos tecnológicos y legales que hagan de las nuevas tecnologías de la comunicación un entorno de negocio seguro. Su filosofía es que la creación y la innovación tienen que revertir un beneficio económico al creador individual y a la estructura económica que lo sustenta. Su argumento principal se basa en que la inversión es condición sine qua non para la creación y la innovación. Proteger el beneficio asociado a la inversión es proteger la producción de conocimiento. Se trata así de acercar el modelo de los derechos de autor al modelo de las patentes industriales.

Algunos marcos alternativos de compresión de las nuevas tecnologías de la comunicación en red ofrecen nuevos modelos de producción y difusión para los productos del «trabajo cognitivo». Inspirándose en el modelo de producción distribuida, en la ética hacker y en los modelos de licencia del copyleft desarrollados desde la filosofía del software libre, aparecen modelos legales de licencia para muchos de los productos de la creación y la innovación que liberan la copia, distribución y modificación de los mismos. Sin duda su aportación más relevante es el análisis del espectro de los diversos derechos asociados a la idea de copyright. Muestran que la elección del autor entre esos derechos de los aplicables a su trabajo puede originar modelos de licencia capaces de conciliar el beneficio personal y social de la creación o innovación. Su filosofía, por tanto, es que la creación y la innovación tienen que revertir un beneficio social e individual. $\mathrm{Su}$ argumento principal se basa en que la publicidad y la cooperación son condición sine qua non para la creación y la innovación. La socialización del conocimiento (su difusión y su apropiación por los individuos) es un movimiento que sólo puede generar más conocimiento. Se trata así de salvaguardar el trabajo cognitivo y sus derechos morales y sociales de los medios y la filosofía de la producción industrial.

La investigación científica no es en absoluto ajena a este debate. En primer lugar y de manera obvia, porque el artículo 10 de nuestra Ley de Propiedad Intelectual $^{2}$ incluye los trabajos de investigación científica entre las obras sujetas a las leyes del copyright, quedando éstos así sometidos a los posibles cambios de legislación propiciados por las nuevas tecnologías. En segundo lugar, porque la metodología de la investigación científica es un buen ejemplo de las ventajas de los sistemas de creación e innovación colectivas. Dichos sistemas son inseparables de la publicidad -y del subsiguiente desarrollo democrático de un código compartido que la posibilita - y van de la mano de las políticas de reconocimiento y prestigio que siguen imperando en el mundo de la investigación académica. La controversia de la propiedad intelectual tiene su reflejo en el debate sobre el carácter público del conocimiento científico y los resultados de sus investigaciones. Dicho debate se extiende a los presupuestos de la financiación de la actividad investigadora en el sector público y al propio papel de la universidad. Por ello, y finalmente, debemos analizar cómo las leyes de propiedad intelectual afectan a la labor de socialización del conocimiento que implícita y explícitamente lleva asociada la investigación científica.

La tarea a abordar es cómo replantearnos estas labores desde las nuevas posibilidades que ofrece la tecnología de la comunicación y buscar los caminos legales que posibiliten la máxima publicidad y 
expansión de los resultados científicos, sobre todo de aquellos propiciados por la inversión pública. Para ello ofreceré un análisis teórico, conceptual y legal de la idea de propiedad intelectual con el objeto de aclarar su contenido y sus relaciones, éticas y sociales, con la publicidad del conocimiento. A la vez, y ante las posibilidades que plantean las nuevas tecnologías, expondré y analizaré la filosofía de nuevos tipos de licencia que propician hacer efectiva de manera práctica y legal la publicidad de nuestras investigaciones a través de los nuevos mecanismos de publicación y distribución que ofrece la red.

\section{El concepto de propiedad intelectual: economía, ética y derecho}

«Propiedad intelectual» es un concepto común en nuestros días que, sin embargo, carece de un referente claramente distinguible. Su uso coloquial se corresponde más con el elemento clave en la agenda de la estructura económica de esta nueva sociedad de la información en la que nos ha tocado vivir: el control de la información. Sociedad del conocimiento o de la información refieren un mismo hecho general: la economía se ha desmaterializado y ha pasado a primer plano la producción de bienes y servicios cognitivos. En un mundo complejo y cambiante adquieren gran valor los servicios que, bien directamente o bien por medio de la tecnología, reducen la complejidad cognitiva de las tareas. La PI surge como un concepto lato que debe cubrir este renovado valor económico del conocimiento. Sin embargo, desde un punto de vista económico, ético y legal la «propiedad» de los resultados del trabajo cognitivo se justifica, se valora y se rige desde muy diversos marcos que sugieren una distinción clara de diversos tipos de propiedad aplicada a lo intelectual.

Para comenzar, debemos considerar en qué sentido es apropiable la información.
Es un lugar común admitir que la información en general es un bien público. Desgraciadamente, desde conceptos puramente económicos esto no es totalmente cierto. Los bienes públicos deben cumplir dos principios: la indisputabilidad y la inexclusividad. Por ejemplo, el alumbrado público es un bien no rival porque su utilización por un individuo no afecta al uso que puedan obtener otros individuos. No hay rivalidad o disputa para beneficiarse del alumbrado; en otras palabras, los beneficios que proporciona son indivisibles. Además está ahí para prestar servicio a todos los ciudadanos sin exclusión. Nadie queda excluido de su uso porque, por ejemplo, no pague impuestos a su ayuntamiento; en otras palabras, ningún individuo puede apropiarse privadamente de sus beneficios. La información parece cumplir con estos requisitos. Más directamente con el de la no-rivalidad: el uso que yo haga de una «idea» no afecta al posible uso de los demás, luego no debe existir rivalidad. Con un poco más de dificultad se justifica la no-exclusividad: la información codificada en algún medio puede ser accesible a todo el mundo y nadie tendría por qué quedar excluido de su acceso. Pero la información, para ser accesible, debe ser codificada en algún lenguaje y materializada en algún soporte. Lo último afecta al carácter de la rivalidad: si bien la idea no tiene valor material, sí lo tiene el objeto en el que se materializa y su posesión puede generar rivalidad. Lo primero afecta a su exclusividad: el sistema de signos y reglas que sirve para codificar la información excluye a aquellos que no lo conocen y, por tanto, no pueden interpretar la información ni, consiguientemente, extraer beneficio de ella ${ }^{3}$. La mayor parte de la información de tipo cultural está codificada en lenguajes que, en mayor o menor medida, comparten todos los integrantes de una comunidad y cuyas reglas son públicas y accesibles para ser aprendidos por los miembros de otras comunidades. 
Por ello, no solemos pensar en la exclusión en razón del sistema de codificación de la información. Conocer esos códigos es parte de nuestro proceso de socialización en la comunidad en general y en nuestro entorno específico en particular. El problema de la codificación se puede soslayar siempre que los códigos sean accesibles a los individuos ${ }^{4}$. Estudiar la propiedad intelectual bajo la perspectiva puramente económica nos conduce a justificaciones de la apropiación de las ideas en virtud de la inversión necesaria para dotarlas de soporte material.

Pero las ideas, antes de ser materializadas, ya son el producto del trabajo de las personas, por lo que el estudio de su dimensión pública desde los conceptos de no-rivalidad y no-exclusividad se me antoja insuficiente. Desde un punto de vista ético y filosófico, el esfuerzo de creación de ideas aún en su dimensión inmaterial debe obtener recompensa justa como labor (Hughes, 1988). Y más allá, una recompensa moral en la medida en que la obra intelectual es expresión de la personalidad de su autor. Pero estas recompensas al individuo creador deben someterse a dos consideraciones de tipo social y comunitario:

1) Cualquier obra intelectual se construye desde una circunstancia vital e intelectual concreta que se adquiere mediante el aprendizaje social y gremial. Por tanto, garantizar el derecho de los individuos a acceder a la mayor cuota posible de información colectiva supone la condición básica que posibilita la creación individual.

2) El trabajo cognitivo es socialmente valioso y valorable en la medida en que sus productos pasan a ser de dominio público $\mathrm{y}$, por tanto, cuerpos de información básicos para la construcción y el incentivo de creaciones posteriores. Garantizar el acceso de todos los individuos al mismo volumen de información debe constituirse en principio ético de una distribución equitativa de la justicia social (Lipinski y Britz, 2000).

La valoración ética de la creación intelectual individual es, por tanto, inseparable de la posibilidad de apropiación social de esa obras ${ }^{5}$. Diseñar mecanismos que recojan el justo equilibrio de ambos es el cometido de la legislación sobre propiedad intelectual.

Las leyes sobre propiedad intelectual ${ }^{6}$ recogen esta filosofía y reconocen como motivación principal la definición y protección de una serie de derechos de explotación sobre los usos comerciales de las obras artísticas, literarias y científicas. La protección de dichos derechos pretende garantizar el incentivo a la creación y a la difusión y promoción de la cultura y con ello el aprendizaje y desarrollo cultural. Pero siempre desde la perspectiva de que el fin último de las obras es su utilización en el dominio público (como queda definido en el art. 41 de la LPI). Para ello se desarrollan una serie de limitaciones sobre los derechos de explotación de la obra que definen un concepto temporal y relativo sobre la propiedad de lo intelectual.

Temporal, porque los derechos económicos sobre la explotación de la obra no son permanentes, sino que tienen un plazo de expiración, generalmente setenta años después del fallecimiento del autor. Relativo, porque la PI queda limitada para determinados usos de la obras. Este tipo de «usos legítimos», contemplados en los artículos del título II de nuestra Ley (destacan el 32, 33, 37, 38 y 39), recogen el derecho de usar libremente las obras literarias, artísticas y científicas con fines educativos y culturales. También se consideran usos legítimos amparados por la Ley la copia privada o el préstamo. En todos los casos, el criterio básico para definir un uso como legítimo es su propósito o carácter. Estarán limitados, en general, aquellos usos de la obra que tengan carácter lucrativo. 
Queda así definido un marco legislativo que dota al concepto de propiedad de características formales especiales en atención a la dimensión ética de la labor de creación intelectual. El simple hecho de la creación asegura los derechos morales del autor sobre la obra. Al aplicar el copyright, se aseguran los derechos económicos, temporales y no absolutos, sobre la reproducción, distribución, adaptación y presentación pública de la obra.

El copyright se puede relacionar con las patentes, marcas y secreto industrial, en la medida en que son diferentes marcos legislativos que afectan a actividades de creación en las que lo intelectual juega algún papel. Podemos observar cómo gran parte de la literatura sobre la propiedad de la información los unifica calificándolos como regímenes de propiedad intelectual ${ }^{7}$. Esta homogeneización está dirigida a reforzar la dimensión privada y económica de los derechos de propiedad de los productos del intelecto frente a la dimensión social del conocimiento. El argumento común para la defensa de un marco tan general de la PI se basa en la idea de que todo trabajo cognitivo para producir «obras del intelecto» necesita de un incentivo económico. Sin embargo, un análisis básico sobre la fuente, forma y cuantía del incentivo prueba que esta justificación de tipo económico no se reduce al acto en sí de la creación, sino que se basa en actividades económicas paralelas a la materialización y difusión de la creación ${ }^{8}$. Por tanto, los mecanismos de concesión de los derechos sobre obras intelectuales deben seguir, como hasta ahora, bajo supuestos legales que garanticen un beneficio económico justo y suficiente por dichas actividades paralelas, sin que ello perjudique a los derechos de apropiación del conocimiento implícito por parte de los ciudadanos.

El problema al que nos enfrentamos en los albores del siglo XXI es que la tecnología digital rompe este equilibrio entre las dimensiones económica y social de la creación intelectual. Desde el punto de vista económico, porque la fidelidad de la copia digital y la posibilidad de la su distribución a través de Internet puede desvalorizar muchos de los componentes materiales de la labor de los editores. Pero, a la vez, esas posibilidades tecnológicas facilitan los usos legítimos de la información y el conocimiento y, por tanto, las posibilidades de acceso de la sociedad a ese acervo cultural. Encontrar un nuevo equilibrio legal que concilie ambas dimensiones parece complicado.

Pero desde el punto de vista legal aún tenemos otro problema añadido. Cuando la información se digitaliza se aseguran mecanismos de exclusividad de la información, por cuanto el código ahora protege la posterior traducción de la información a los formatos no digitales y sus usos posteriores. Como bien señala Lessig (1999, p. 201 cap. 10) la Ley sobre la propiedad garantiza una cierta protección sobre, digamos, mi coche. Si alguien me lo roba la Ley me garantiza la persecución del delito y la - poco probable - restitución del bien enajenado. Si tuviera especial aprecio a mi coche, puedo instalar todos los mecanismos antirrobo del mercado para prevenir el hurto. La Ley no me impide usar todos los medios a mi alcance para proteger mi propiedad y eso no contradice la ley. El movimiento actual de las grandes corporaciones empresariales de la industria digital es el diseño de estrategias tecnológicas y legales para llevar a cabo este control por su cuenta.

La tecnología hace posible el control total de todos los usos de las obras digitalizadas. La propiedad de los formatos digitales condiciona el medio de reproducción de las obras y posibilita la aparición de nuevos tipos de licencias temporales de uso. La tecnología digital permite la distribución bajo licencias «de rompe y rasga» (click-wrap o shrink wrap licenses) (Einhorn, 1998). Pagamos derechos para 
reproducir la obra una vez, un número determinado de veces, o durante un período de tiempo electrónicamente fijado. Estas licencias atentan contra los plazos de apropiación pública de las obras. Recordemos que los derechos de autor son temporales y que las obras pasan a ser de dominio público cumplido el plazo correspondiente. Si la tecnología impide que reproduzcamos la obra en un plazo acordado contractualmente, pasado ese plazo no podremos reproducir la obra de ninguna manera y, por tanto, no se podrá hacer efectiva la apropiación pública en los plazos legales porque, simplemente, la tecnología de control lo impedirá. Sería curioso asistir a la perplejidad de un antropólogo del siglo XXV tratando de estudiar un CD con alguna obra intelectual del siglo XXI y que se encontrara con un aviso del tipo «la licencia para visualizar el contenido de este CD ha expirado; póngase en contacto con su distribuidor más próximo».

La tecnología TCPA ${ }^{9}$ - Trusted Computing Platform Alliance- (Alianza para una Plataforma de Computación «de Confianza») es el mejor ejemplo de la política de las grandes corporaciones (Microsoft, Intel, AMD, IBM, Sony, etc.) para ejercer el control total sobre el material sujeto a copyright. Dicho control se ejercería a nivel del hardware, dotando a las computadoras de sistemas de control y monitorización vía Internet del software y material licenciado.

Legalmente, este tipo de iniciativas tecnológicas encuentran protección en marcos como el de la Digital Millenium Copyright Act en Estados Unidos ${ }^{10}$. Uno de sus efectos más significativos es que tipifica como delito la llamada ingeniería inversa ${ }^{11}$. Concretamente, prohíbe la fabricación, importación o distribución de «dispositivos, productos y componentes que eludan los métodos tecnológicos que impiden el uso no autorizado». Es decir, garantiza la privacidad absoluta del código, y con él, el control de todos los pro- ductos de conocimiento así codificados. La propiedad intelectual deja de ser relativa, pues la tecnología impide la posibilidad de ejercer usos legítimos contemplados y permitidos por la ley ${ }^{12}$.

Las nuevas tecnologías de la comunicación, especialmente Internet, parecen plantear dos posibilidades a los autores: 1) utilizarlas para copiar y difundir su obra sin coste alguno y casi en tiempo real a través de la red, es decir, de manera autónoma e independiente de los editores; 2) seguir cediendo los derechos de explotación a los editores aun a riesgo de que las posibilidades de control de la tecnología digital propicien la pérdida de alguno de sus derechos morales convirtiendo la PI en propiedad absoluta.

La elección va a depender de criterios económicos, sociales e intelectuales, con la consideración de que esos criterios deben ser los del autor y no los de sus editores. A continuación enunciaré diversas posibilidades legales de tipo práctico para ampliar la capacidad de elección y control de los autores en función del tipo de licencia que decidan aplicar a su obra.

\section{Contra la exclusividad del copyright: derechos de autor «a la carta»}

El debate sobre las leyes de propiedad intelectual se plantea habitualmente desde posiciones extremistas. El control total de todos los derechos, como promueven los grandes grupos empresariales, o la alternativa del derecho a la copia completamente libre e, incluso, la piratería como lucha activa legítima para eludir las apropiaciones que sobrepasan la ley y perjudican a la comunidad en su conjunto.

No considero una buena idea acabar con la protección de las leyes de propiedad intelectual. En primer lugar, por una razón puramente práctica: cualquier contrato o batalla legal sobre los derechos morales y de control de una obra por su autor sigue 
sometido a dichas leyes. Por tanto, el derecho de un autor a liberar su trabajo y ofrecerlo públicamente, evitando cualquier tipo de apropiación privada, también estará protegido por esta legislación.

En segundo lugar, por razones éticas y filosóficas. La filosofía de la propiedad intelectual expresa un equilibrio entre el interés público y el interés económico del autor. El incentivo al desarrollo creativo del trabajo intelectual está justificado si se piensa desde el punto de vista del beneficio que la creación intelectual reporta a la comunidad, no del beneficio económico que reportan las actividades a él asociadas (aunque uno no tiene más que acercarse a la prensa o a la televisión para comprobar cómo los indicadores económicos marcan la valoración del beneficio comunitario: «si la economía va bien, la sociedad va bien»). Los derechos de explotación recogidos en la LPI sustentan una base legal amplia para que el propio autor fije las condiciones de explotación de su obra garantizando, si es su deseo, que ésta se ajuste a un conjunto de valores más amplios que el simple beneficio económico.

Finalmente, y si las leyes de PI no son modificadas y mantienen esta filosofía, pueden servir como arma legal contra las tecnologías de control. Ya vimos cómo el uso abusivo de las tecnologías de control de la información atenta contra la defensa de los plazos para la apropiación pública y los derechos de uso legítimo contemplados por la ley. Sólo apoyándonos en la ley podemos combatir la apropiación indebida y la sobreprotección tecnológica. Pero podemos esperar a que la máquina judicial se ponga en marcha para cuestionar monopolios o prácticas abusivas, o podemos anticiparnos a los editores definiendo legalmente nuestra posición en cuanto al grado de acceso público que queremos otorgar a nuestra obra.

Parece razonable, por tanto, que participemos activamente como autores en el debate de la PI. Teóricamente, poniendo de manifiesto la dimensión ética y social de la LPI y la necesidad de un acceso justo y libre a la información básica. Desde un punto de vista práctico, defendiendo el uso de modelos de licencia alternativos, pero no opuestos, al copyright que protejan de manera efectiva nuestra posición teórica. Ese tipo de modelos deben oponerse a la exclusividad del copyright mediante la selección y articulación y de los distintos derechos componentes del copyright para redactar licencias de uso alternativas. A continuación expondré alguno de los tipos existentes de licencias alternativas para obras intelectuales que concilian amplias libertades de los usuarios con el reconocimiento de los derechos morales del creador.

El caso más conocido, y muchas veces mal interpretado, es el llamado copyleft, proveniente del mundo de software libre. Este caso es un buen ejemplo de un concepto de propiedad intelectual pública. Bajo la broma de la tergiversación de los habituales Copyright. All rights reserved bajo los nuevos Copyleft. All rights reversed se esconde un tipo de licencia para el libre uso, modificación, copia y distribución de productos de software ${ }^{13}$. El «copyleft» nos interesa como ejemplo de que la legislación asociada al copyright protege las bases legales del copyleft y con ello su mecanismo incentivador. Porque el copyleft surge como mecanismo legal protector e incentivador de un sistema de producción distribuida del software. La filosofía del software libre, sobre todo desde el advenimiento de Internet como espacio productivo, ha concebido el desarrollo del software como un trabajo colaborativo. La colaboración exige que los participantes puedan copiar y modificar libremente aquellos programas que les interese desarrollar y mejorar. Además, deben poseer el incentivo de que sus desarrollos se puedan difundir y comercializar para obtener beneficios a través del reconocimiento y la redistribución. Pero el negativo efecto, «el primero que lo registre es el dueño», que 
poseen las leyes de copyright y patentes proporcionaba un marco legal para interrumpir este proceso en el momento en que un programador decidiera registrar/patentar ${ }^{14}$ su desarrollo, apropiándose para sí todas las ideas del programa en las que se había basado y que habían sido desarrolladas previamente. El copyleft asegura que cualquier obra derivada debe ser también copyleft $\mathrm{y}$, por tanto, va a poder ser usada $\mathrm{y}$ modificada libremente por los demás programadores y usuarios.

Técnicamente, el copyleft asegura la transmisión de los efectos de la licencia original a las licencias de los programas derivados. Así preserva el carácter del software libre, prohibiendo que desarrollos basados en programas con licencias copyleft, se licencien o se redistribuyan con restricciones adicionales. Esto lo logra apoyándose en tres elementos (Nonius, 2002). Una sujeción: no cabe explotación del programa derivado si no es en los mismos términos copyleft. Una obligación: la de ajustar la redistribución a los términos del copyleft, poniendo a disposición de los receptores de un programa copyleft o sus derivados una licencia GPL sin restricciones adicionales. Una carga: la de exigir el permiso del autor para legitimar el uso de partes de su programa a otros programas libres con condiciones de distribución distintas.

El copyleft, por tanto, no se contrapone al copyright. Preserva los derechos morales del autor pero deja libres los derechos de explotación a cambio de que las obras obtenidas de la copia y modificación de los originales mantengan y fomenten el uso compartido y la reutilización del software. La libertad de modificación exige el acceso completo al código fuente del programa. La publicidad del código implica la accesibilidad y publicidad del conocimiento asociado y asegura la continuidad del proceso productivo. La libertad de copia y distribución asegura, desde el punto de vista del autor, la posibilidad de la popularización de su producto y con ello el reconocimiento y las retribuciones indirectas asociadas: mantenimiento del programa, desarrollo de aplicaciones específicas, formación de los usuarios, beneficios de los costes de distribución, etc. Evidentemente estos beneficios no son tan altos como los que se derivarían del cobro de derechos sobre patentes o licencias. El problema es que en el caso del software esos elevados beneficios son producto de los mecanismos formales y no se corresponden con la inversión necesaria para el desarrollo de los productos, sino más bien con la inversión para invadir y monopolizar el mercado.

El concepto de copyleft ha demostrado una perfecta adecuación a los requisitos de desarrollo colaborativo de software. La modularidad y composicionalidad propias de la arquitectura de los programas ha favorecido sin duda este sistema de producción distribuida. Al fin y al cabo los programas no son más que secuencias algorítmicas y su creación está al alcance de cualquiera. La suma de esfuerzos colaborativos es suficiente para un desarrollo y control continuo y eficiente. No se necesitan grandes inversiones en medios e investigación que pudieran justificar su apropiación privada mediante patentes. Distribuciones de software como el popular GNU/Linux demuestran la eficiencia de este tipo de licencias para incentivar la producción intelectual a través de beneficios indirectos para el autor. Más aún, el fenómeno del software libre contradice la presuposición de los defensores de la restricciones de la PI de que no hay otra forma de lograr el progreso que afianzar los mecanismos de remuneración directa del autor y los editores.

El modelo de copyleft para el software ha tenido una aplicación inmediata al mundo de la documentación: la licencia de documentación libre FDL (http://www. gnu.org/copyleft/fdl.htm) ${ }^{15}$. Dicha licencia se concibió para los propios manuales de 
software libre, por cuanto las sucesivas modificaciones del software requerían las consiguientes modificaciones de los manuales. Sin embargo, al considerar la redacción de dicha licencia, se observó la necesidad de restringir la libertad de aquello que podía ser modificado, precisamente los párrafos que no son estrictamente técnicos. Así la licencia FDL asegura la libre modificación del contenido técnico, pero restringe la del contenido valorativo y personal que expresa ideas u opiniones subjetivas del autor.

Este ejemplo nos pone de manifiesto que la licencia GPL no es aplicable de manera sencilla a los distintos productos de la actividad intelectual ${ }^{16}$. El propio Richard Stallman, cabeza visible de la Free Software Foundation y teórico e impulsor del desarrollo colaborativo y libre de software, ya da cuenta de estas dificultades en Stallman, 2000. Su planteamiento se basa en que, si bien es interesante considerar la posibilidad de reducir el campo del copyright para que no afecte a los intercambios naturales de información (la mayoría de los que hemos recogido bajo el «uso legítimo»), debemos hacerlo teniendo en cuenta el tipo de obra intelectual. Para ello propone la clasificación de las obras en tres tipos: 1) obras funcionales; 2) obras que expresan posiciones personales, y 3) obras que son fundamentalmente estéticas.

Las obras funcionales incluirían aquellos esquemas prácticos sobre un «mundo objetivo» cuyo cometido sea ayudar a llevar a cabo una determinada tarea. El software, recetas, libros de texto, diccionarios, obras de referencia, etc., son ejemplos de este tipo de obras. Para estos casos, Stallman considera que una licencia abierta de tipo FDL es la apropiada, pues la gente debe tener libertad para usar, transmitir y modificar este tipo de obras que, básicamente, son depositarias del conocimiento y normas sociales más elementales.

Ensayos, artículos, críticas, declaraciones de la postura legal de una persona, memorias y todos los tipos de publicaciones científicas forman parte del tipo de obras que expresan opiniones personales. En este tipo de obras, propiciar el derecho a la libre modificación de la obra implicaría modificar la propia opinión expresada en ella. La propuesta de Stallman es, por tanto, no permitir la libre modificación para este tipo de obras. Si bien la liberación de los derechos de redistribución no comercial son muy beneficiosos para la comunidad, la copia y redistribución debe ser literal. Con ello se preservan los derechos morales del autor que, en este caso, se justifican plenamente por la originalidad de la opinión recogida.

En cuanto a las obras puramente estéticas: novelas, obras teatrales, poemas, dibujos y la mayor parte de la música, Stallman opina que su uso principal es el de ser apreciadas, por tanto, en principio la gente no tendría necesidad de publicar versiones modificadas. Sin embargo, la creación de este tipo de obras siempre está sujeta a una reinterpretación del acervo cultural preexistente, por lo que la idea de la libre modificación ha estado presente en todas las creaciones a lo largo de la historia y sólo ahora se empieza a limitar legalmente este mecanismo artístico. No obstante, la propuesta de Stallman no incluye una respuesta a los dilemas que plantean las obras estéticas.

La clasificación de Stallman, si bien revela diferencias interesantes a la hora de plantearnos cómo conciliar la propiedad intelectual con la publicidad del conocimiento asociado a las obras, plantea muchos problemas a la hora de llevarla a cabo. Las fronteras se diluyen para un gran número de obras que son difíciles de clasificar. Por ejemplo, las propias obras académicas presentan gran diversidad. En principio, parece que los textos de humanidades estarían más cerca del grupo de obras que expresan opiniones personales, mientras que, por ejemplo, una tesis sobre un método de investiga- 
ción en biología podría ser interpretada como obra funcional.

Por eso la propuesta que vamos a defender es que es el propio autor, como depositario primero de los derechos de su obra según la legislación vigente, el que puede y debe elegir el tipo de licencia que considera oportuno aplicar a su obra. Bajo esta filosofía se han desarrollado las propuestas del grupo «Creative Commons» ${ }^{17}$. Este grupo nació en las Facultades de Derecho de Harvard y Stanford y es impulsado por juristas y expertos en propiedad intelectual. Su proyecto es la elaboración de un conjunto de licencias libres para uso público para varios tipos de trabajo creativo: sitios web, música, cine, fotografía, literatura, cursos de enseñanza, etc. CC ofrece una serie de modelos de licencia libre para que el autor elija la más adecuada para su trabajo desde la filosofía de unir directamente los intereses del público con los intereses del creador independientemente de una industria intermediaria. Frente al «todos los derechos reservados» ahora se enfrenta un «algunos derechos reservados».

Los modelos de licencia de CC se articulan diferenciando cuatro restricciones básicas que pueden aplicarse a obras con licencia de copia y distribución libre:

- Crédito (reconocimiento): para asegurar los derechos morales del autor, los derechos de explotación (recordemos: reproducción, distribución, comunicación pública y transformación) quedan sujetos a la condición de incluir el nombre del autor original en la obra copiada o transformada.

- No uso comercial: para evitar perjuicios económicos al autor, los derechos de copia, reproducción y distribución se conceden siempre que éstas se realicen sin ánimo de lucro.

- No obras derivadas: para mantener la integridad de la obra y las intenciones originales del autor se prohíbe la transfor- mación, permitiendo solamente la copia literal.

- Compartir bajo las mismas condiciones: para incentivar la creación colectiva y evitar apropiaciones indebidas, el autor estipula que su obra sólo puede ser modificada para generar nuevas obras si estas últimas se ofrecen al público bajo la misma licencia abierta. (Nótese que esta condición no se puede aplicar si decidimos autorizar sólo la copia íntegra.)

Tras esta descomposición analítica, el grupo de $\mathrm{CC}$ ha emprendido la tarea de redactar diversas licencias para cada posibilidad surgida de las diversas combinaciones de esas cuatro restricciones básicas. Cada licencia estipula una serie de derechos adicionales compatibles con los derechos liberados y está redactada en términos legales que asegurarían la protección de los derechos elegidos y cedidos bajo el marco de las propias leyes actuales de copyright (en este caso las de Estados Unidos, pero en virtud de los tratados internacionales la protección sería similar en otros países). Las licencias que propone $\mathrm{CC}$ son licencias públicas en las que no figura el nombre del autor. Para que un trabajo publicado en Internet pueda acogerse a una de estas licencias basta incluir el texto de la licencia en dicho trabajo u obra o, simplemente, remitir al texto correspondiente publicado en la web de CC mediante un enlace.

Sin duda, el valor más destacable de la propuesta de $\mathrm{CC}$ es que ofrece al propio autor la posibilidad, y con ella la responsabilidad, de elegir el modelo de licencia adecuado para su obra. Es posible argumentar que un control casi absoluto de este tipo por parte del creador puede aún contravenir los valores de un conocimiento públicamente accesible, por cuanto se pueden sobreproteger obras de tipo funcional en las que el papel del autor sea sólo reordenar conocimientos ya existentes en 
el acervo cultural. Pienso que la propuesta hay que analizarla como alternativa a la cesión de todos los derechos a las empresas editoriales. Sin duda los autores manejan un cuerpo de valores mucho más amplio y conectado con los valores de la actividad intelectual que desarrollan. Ante esta disyuntiva propongo confiar en los valores del autor, asociados a su actividad creativa dentro de una comunidad particular, para decidir la licencia sobre su obra. Opción más conveniente que dejarlo todo en manos de una legislación de copyright en los medios digitales cada vez más sometida por los «no-valores» económicos.

Creo que entre todas las propuestas presentadas, los autores tienen un amplio abanico de posibilidades para ofrecer sus obras al público. Una obra licenciada con una combinación «crédito, no uso comercial, no obras derivadas» satisface los requisitos del autor más exigente que pretenda difundir su obra sin perjuicio de ninguno de sus derechos morales y respetando totalmente los usos legítimos, independientemente del medio tecnológico en el que publique su obra. Llamaré «licencia abierta» a cualquier combinación de estos derechos básicos que permita la copia y distribución de obras en formato digital y, por tanto, la proteja de apropiaciones indebidas por medios tecnológicos.

Un trabajo legal que aún quedaría por hacer es la redacción de contratos públicos y ajustados a la LPI que hagan compatibles los derechos de edición en medios «materiales» con la libertad de difusión a través de la red. Es justo que aquellos que generen algún valor sobre una obra, en base a un procesamiento intelectual o material, reciban recompensa por ello. El requisito de uso no comercial de las posibles copias en formato digital debería ser suficiente para garantizar que no se lesionan los derechos del editor sobre el valor de la edición material. Éste podría someter la protección de su trabajo editorial a las propias leyes de competencia en el merca- do: una buena edición con una buena distribución será más apreciada por el consumidor. No obstante, se pueden estudiar mecanismos para que el editor se reserve ciertos derechos sobre la presentación material del trabajo, lo que no es igual que reservar los derechos sobre toda la obra intelectual. Estos derechos justificarían el incentivo al trabajo editorial, entendiendo ahora ese trabajo en su dimensión puramente material. No obstante, el mundo editorial no debería temer este tipo de propuestas. La Free Software Foundation o el colectivo WuMing ${ }^{18}$ llevan años publicando libros con licencias libres que ellos mismos ofrecen gratuitamente en la red. Las ventas se benefician de esta publicidad y difusión y los editores obtienen beneficios más que considerables sin necesidad de apropiarse de los derechos de autor.

Evidentemente este planteamiento hace que pierdan justificación los contratos que los editores firman para financiar los trabajos de los autores. Si el editor sólo se queda con los derechos materiales y no se apropia de todos los derechos de explotación, no le interesará pagar a los autores. Esto puede limitar, y de hecho lo hace, el incentivo a la creación. Las posiciones más alternativas abogan por el establecimiento de una «renta básica» para autores y creadores que incentive un trabajo intelectual cuyo destino último es la apropiación por la sociedad. Hay que notar que lo que aquí se propone es eludir estos marcos extremistas, en lo puramente comercial o en lo absolutamente libre, y dar armas legales, culturales y éticas al autor para que decida el alcance de la protección de su trabajo intelectual, mediante licencias abiertas públicas y mediante contratos legales y públicos de cesión de derechos muy específicos sobre la edición y distribución. El autor debe tener la última palabra sobre el punto de equilibrio entre el grado de beneficio económico y de apropiación social en que se sitúa su trabajo. 
Creo que hay muchos colectivos de autores cuya ética y condiciones de financiación y producción les impele a reconocer que su trabajo debe ofrecerse libremente para su apropiación social. Los investigadores científicos, cuyo trabajo es financiado y desarrollado en instituciones públicas, son el mejor ejemplo de este tipo de colectivos.

\section{Investigación pública en la red}

En lo dicho hasta ahora, se ha puesto de manifiesto que es necesario precisar el número y contenido de los derechos que deben proteger las obras intelectuales en función del carácter de la obra y los deseos del autor. Ante la disyuntiva que se nos plantea con las posibilidades la tecnología digital - libertad total de copia y distribución o sobreprotección - debemos posicionarnos de manera activa licenciando nuestros trabajos con el modelo que más se adecue a la ética de nuestra producción intelectual. En este apartado, y como conclusión, se propone que los resultados de las investigaciones financiadas por instituciones públicas deben publicarse en la red con licencias abiertas que faciliten su máxima difusión ${ }^{19}$.

La investigación científica y humanística ha supuesto un denodado intento de comprender la naturaleza y el ser humano. Se ha cimentado históricamente en un ideal de búsqueda del conocimiento por sí mismo. Ese valor ideal ha estado siempre impregnado por los valores personales y sociales - contextuales - de los científicos; influencia más acusada en la investigación humanística que en la científica, quizá porque su papel en el pasado ha estado más unido a la elaboración y transmisión de los conceptos y marcos de comprensión de lo real compartidos por la comunidad. Pero el desarrollo histórico de la ciencia se ha fraguado en instituciones, procedimientos y valores derivados que han constreñido, hasta cierto punto, esta influencia. Instituciones como los centros públicos de investigación y los departamentos universitarios, junto con el procedimiento básico del libre intercambio, revisión y crítica de la información, han fundamentado esta estructura del conocimiento que ha posibilitado la sociedad moderna. Dicha estructura explica el carácter colectivo y socializador de la empresa del conocimiento y, con ella, un gran número de los elementos básicos de nuestra cultura occidental. Bajo criterios puramente económicos no se justifica el carácter público del conocimiento científico (Broncano, 2001; Vega, 2001). Debemos atender a la normatividad de la actividad de los investigadores y a la legitimación institucional de los mecanismos de producción y difusión del conocimiento para justificar la publicidad del conocimiento (Vega, 2001) y su papel socializador.

Todo ello justifica que los Estados modernos sostengan económicamente los sistemas educativos, así como la institución universitaria en particular como centro neurálgico de las labores de producción y socialización del conocimiento. Siendo la libre difusión un elemento clave en esas dos actividades, propongo que las investigaciones financiadas, total o parcialmente, con fondos públicos sean publicadas en Internet con licencias abiertas. De este modo se pondrían a disposición de toda la comunidad científica los resultados para su revisión y crítica, sin la mediación de los lentos mecanismos editoriales de publicación y distribución. Al mismo tiempo, se pondría a disposición de los ciudadanos un conocimiento por el que han pagado parte de sus impuestos y que serviría para el necesario movimiento de socialización de conocimiento y sus valores. Como efecto derivado, se igualarían las posibilidades de publicación y difusión de todos los autores. La relevancia de los textos y la popularidad y el prestigio no 
tendrían otra medida que la relevancia de lo publicado dando más oportunidades de difusión a estudios novedosos y heterodoxos.

Los argumentos en contra de esta idea pueden ser de tipo académico o económico. En el primer caso podemos hablar del aumento indiscriminado de publicaciones y la ausencia de mecanismos de selección (el incremento de información no significa necesariamente aumento de conocimiento: a mayor información, mayor ruido). Pero creo positivamente que estos problemas están ya presentes en el ámbito de la edición impresa. El ingente número de publicaciones impresas hace que su relevancia deba ser evaluada según índices particulares para cada materia. Esos índices podrían incluir perfectamente las páginas web de departamentos o instituciones investigadoras, legitimando su trabajo de selección de los textos, y por tanto la relevancia de los mismos, que se lleve a cabo antes de la publicación en la web. Exactamente los mismos mecanismos de ajuste que requieren las miles de publicaciones impresas. El corporativismo que amenaza los actuales servicios de publicaciones de las universidades, y los intereses editoriales subyacentes que siempre distorsionan la imparcialidad de las revistas científicas, son formas del problema de la selección de textos que ya están presentes en el mundo de la edición impresa.

Desde el punto de vista económico, se puede argumentar que la libre copia y difusión acabaría con el negocio editorial, sobre todo con el de la edición de revistas especializadas. En este punto se hace necesario un análisis del negocio editorial relacionado con la investigación científica y humanística. En este caso los editores no realizan ninguna inversión relacionada con el incentivo de la investigación. En la mayoría de los casos, los autores no sólo no obtienen dinero de los editores por la cesión de sus derechos, sino que es práctica común que las editoriales cobren un canon por página publicada, que suele ser pagado mediante los fondos dedicados a la investigación. Además, ya es un procedimiento habitual en la comunidad investigadora obtener los artículos mediante fotocopias en las bibliotecas (amparados por el art. 37 de la LPI). A pesar de algunos famosos procesos judiciales contra estas prácticas ${ }^{20}$, el tiempo ha demostrado que estas prácticas contra la exclusividad del copyright no han afectado a los resultados económicos de las empresas editoras.

Las revistas científicas sólo pueden basar su argumentación de tipo económico en base a las inversiones para llevar a cabo la labor de estudio y selección imparcial de los trabajos de investigación, así como los costes de elaboración de la edición impresa. Creo que el montante total de estas labores no justifica la apropiación en exclusiva de todos los derechos de explotación de los trabajos de investigación hasta impedir, por ejemplo, su publicación en Internet con licencias libres. La publicación de un texto en la página web del autor no conlleva ningún proceso de selección. Puesto que las revistas especializadas basan su negocio en dicho proceso de selección - normalmente llevado a cabo por investigadores de prestigio convenientemente remunerados por ello-, este tipo de prácticas en la red no afecta a su negocio. La posibilidad de copiar libremente los textos desde Internet no anula el interés de bibliotecas, departamentos e investigadores particulares en la adquisición de revistas prestigiosas que seleccionen y agrupen esos textos conforme a criterios científicos rigurosos. Publicar los trabajos de investigación en la red con licencias abiertas no se opone al negocio editorial si esas licencias incluyen una cláusula «comparta bajo la misma licencia», es decir, se restringe la copia a usos no comerciales (que no suelen diferir de los usos legítimos reconocidos por la comunidad científica). El autor aún puede otorgar los dere- 
chos exclusivos de una edición impresa con beneficio económico a la empresa editora que él considere conveniente. Incluso podemos sortear un tanto la presión de los editores proporcionándoles en exclusiva recopilaciones, capítulos adicionales, etc., lo que no impediría que las ideas, datos y argumentos principales del trabajo estuvieran previamente publicados con licencias abiertas. Ahora la publicación en la red bajo el marco de una licencia abierta sólo va a significar que se pone la obra a disposición del público general. Pero parte de ese público va a seguir valorando la labor de selección de las revistas científicas y, por tanto, va a consultar revistas en las bibliotecas y centros académicos. Por ello las bibliotecas y centros de investigación seguirán comprando las ediciones impresas, facilitando su consulta a sus usuarios. Y aún una parte significativa de ese público va a valorar el carácter objetual de las publicaciones y comprará revistas, recopilaciones temáticas y libros con ediciones seleccionadas y cuidadas. Es decir, no va a desaparecer el más que justificado componente material del negocio editorial. Es más, los mecanismos de publicidad y difusión en la red van a ayudar a que aumente la popularidad de las ideas de los autores y con ello la demanda de ediciones seleccionadas y cuidadas de sus obras.

La publicación de los resultados de la investigación financiada públicamente en la red garantizará un acceso libre y gratuito a ese conocimiento a quien desee usarlo con cualquier fin social o intelectual sin ánimo de lucro. Este tipo de publicidad del conocimiento ya está contemplada en la ley y puede ser puesta en práctica sin más ${ }^{21}$. La propuestas de usar licencias abierta explícitas en el texto quiere ir un poco más allá en la dirección de una defensa políticamente activa de esos usos legítimos que la sobreprotección tecnológica puede amenazar. No trata de ir en perjuicio de negocios asociados a los mecanismos de selección y edición editorial. Los mecanismos abiertos y colaborativos nunca cierran la posibilidad de los entornos de negocio justificados. Pero los mecanismos formal, legal y tecnológicamente sobreprotegidos sí pueden dañar los mecanismos de libre transmisión de la información. La propuesta de las licencias abiertas va a encaminada a proteger esta pluralidad y con ella la publicidad y sociabilidad del conocimiento. Espero haber contribuido a exponer la teoría y la praxis para llevar a cabo este movimiento.

\section{BIBLIOGRAFÍA}

Bently, L., y Maniatis, S. M. (eds.): Intellectual Property and Ethics, vol. 4, Londres, Sweet Maxwell, 1998.

BroncAno, F.: «¿Es la ciencia un bien público?», Claves de Razón Práctica, núm.115, 2001, pp. 22-28.

Drahos, P. A.: Philosophy of Intellectual Property, Hants, England, Dartmouth Publishing Company Limited, 1996.

EINHORN, D.: «Shrink-wrap licenses: the debate continues», Idea. Journal of Law and Technology, núm. 38, 1998. http://www.idea.piercelaw.edu/ articles/38/38_3/12.Einhorn.pdf.

FELTRERO, R.: «Conceptos, valores y nuevas tecnologías: una perspectiva dinámica», Thauma, núm. 1, 2003, pp. 43-47.

Goldstein, P.: Copyright's Highway. Nueva York: Farrar, Straus \& Giroux, Inc. Vers. cast. de M. L. LlobreGAT: El copyright en la sociedad de la información, Alicante, Universidad de Alicante, 1994.

Hughes, J:. «The philosophy or Intellectual Property», Georgetown Law Journal, núm. 77, 1988, pp. 287-366. http:// www.law.harvard.edu/Academic_Affairs/coursepages/tfisher/music /Hughes 1988.html.

LESSIG, L:. Code and other laws of cyberspace, Nueva York, Basic Books, 1999. 
LIPINSKI, T. A., y BRITZ, J. J.: «Rethinking the ownership of information in the 21st century: Ethical implications», Ethics and information technology, 2000, núm. 2, pp. 49-71

Nonius, J.: Introducción a las licencias de software libre, 2002 Disponible en: http://laespiral.org/documentacion/arti culos/licencias/licencias.html (marzo 2003).
Stallman, R.: El copyright contra la comunidad en la era de las redes de ordenadores, 2000, Disponible en: http://sindominio.net/biblioweb/telematica/stallman-copyright.html (marzo 2003),

VEGA, J.: «Ciencia privada, conocimiento público», Isegoría, núm. 25, 2001, pp. 247-261

\section{NOTAS}

${ }^{1}$ La redacción de este trabajo se ha beneficiado del proyecto de investigación del Ministerio de Ciencia y Tecnología I + D BFF2002-03656, del proyecto de investigación de la UNED 2001V/PROYT/03Humanística y Social y de la beca predoctoral de la UNED que disfruto. Agradezco a Eulalia Pérez Sedeño la posibilidad que me brindó para plasmar públicamente estas ideas y a Eduardo de Bustos y Francisco Álvarez su continuado apoyo y sus inteligentes apreciaciones sobre el mismo. Este trabajo no hubiera sido posible sin la encomiable labor de los defensores de este tipo de filosofía colaborativa para la producción del conocimiento que organizaron las Jornadas Críticas sobre la Propiedad Intelectual en Madrid (http://sindominio.net/copyleft) y a los otros muchos que prestan desinteresadamente su trabajo, material y cognitivo, en los lugares de Internet que aparecen como fuentes electrónicas en este texto y que invito a visitar y conocer. Una versión desarrollada de muchos de los argumentos aquí sólo apuntados se puede encontrar en http://www.uned.es/dpto_log/rfeltrero en un texto con licencia abierta.

2 Se cita dicha Ley según el Real Decreto Legislativo 1/1996, de 12 de abril, (BOE 22-4-1996), por el que se aprobó el texto refundido de la Ley de Propiedad Intelectual (LPI) y que se encuentra disponible en http://www.mcu.es/Propiedad_Intelectual/anexos/Ley Prop_Intelectual_mod171.pdf.

${ }^{3}$ Este argumento está inspirado en el que Jesús Vega (2001) desarrolla con gran precisión para el problema del conocimiento científico.

${ }_{4}$ Desgraciadamente, veremos cómo en la era digital la apropiación de los códigos se convierte en el principal impedimento para la socialización del conocimiento. Ahora el código sirve también para dar soporte material, como información digitalizada, a los productos del conocimiento. La apropiación de los códigos de digitalización y transmisión impide la difusión y apropiación del conocimiento aun cuando se domine el código para interpretarlo.
5 Postura similares sobre la fundamentación ética de la propiedad intelectual se pueden encontrar en Bently y Maniatis, 1998; Lessig, 1999; Lipinski y Britz, 2000.

${ }^{6}$ Existen diferencias técnicas y legales significativas entre las leyes anglosajonas y las europeas. La más importante es que en Europa se reconocen derechos morales inalienables del autor. Usaremos ciertos conceptos, como el de «uso legítimo», en su acepción más general teniendo en cuenta que, aun siendo un concepto legal proveniente del mundo anglosajón, su filosofía y motivaciones se pueden encontrar en la redacción de diversos artículos de las leyes europeas.

7 No en vano la política de internacionalización y unificación de los mecanismos de patentes y copyright impulsada por los países occidentales en la segunda mitad del siglo Xx ha propiciado este sentido lato del concepto. Así, el artículo 2 del Convenio de 14 de julio de 1967, que establece la Organización Mundial de la Propiedad Intelectual, incluye dentro de la misma los derechos relativos a las obras literarias, artísticas, científicas y los correspondientes a su ejecución y distribución, junto a los derechos relativos a las invenciones, a los descubrimientos científicos, a los dibujos y modelos industriales, a las marcas, a los nombres y denominaciones comerciales, e incluso la protección contra la competencia desleal.

${ }^{8}$ En nuestros días el esfuerzo económico más importante es la inversión en marketing y publicidad. Es sencillo argumentar que habitualmente las obras promocionadas con mayor inversión son las de menor valor cultural y social.

9 http://www.trustedcomputing.org.

$10 \mathrm{http} / / / \mathrm{www} . l o c . g o v /$ copyright/legislation/dmca. pdf, ver también http://www.eff.org/IP/DMCA/.

11 Merece la pena recordar que la legislación sobre secreto industrial autoriza dicho secreto pero no lo protege. Puesto que una compañía decide no hacer público su descubrimiento mediante una patente y mantener su monopolio mediante el secreto, tenemos 
derecho a tratar de llegar por nuestros propios medios y de manera honesta al mismo resultado. La DCMA atenta así contra el derecho a la creación técnica autónoma.

${ }^{12}$ El mejor ejemplo de lo que decimos es la decodificación del DVD. Un mozalbete noruego llamado Jon Johansenn fue procesado tras descubrir la manera de decodificar el formato DVD. Su única intención fue poder reproducir sus DVDs, por los que había pagado los correspondientes derechos de autor, en su sistema operativo libre. Afortunadamente ha sido absuelto recientemente por la justicia de su país, pues la ingeniería inversa practicada no atentaba contra la legislación en materia de PI. Imaginemos que compramos un coche y sólo lo podemos conducir por determinadas autopistas de que tienen acuerdos con la compañía que diseñó nuestro coche: esto es la TCPA.

${ }^{13}$ Hay varios modelos legales de licencias de software libre BSD, Xfree86, Mozilla, etc. Usamos el texto de la General Public License (http://www.gnu/ copyleft), puesto que es un modelo general que se aplica a varios productos, entre ellos al popular proyecto GNU/Linux, y, sin duda, es la licencia que lleva asociados mayores componentes éticos y filosóficos en su planteamiento.

14 A diferencia de Europa, en Estados Unidos están admitidas las patentes de software, de ahí que la Free Software Foundation, de origen americano, diera tanta importancia a la regulación legal del software libre.

15 Se puede encontrar documentación libre amparada bajo licencias libres similares como FreeBSD Documentation Lic., Apple's Common Documentación Lic., etc.
16 No obstante, hay varios intentos de aplicar la misma filosofía a varios campos de la creación artística. Se pueden encontrar ejemplos en OpenContent, http://opencontent.org, Open Music Registry, http://www.openmusicregistry.org/ o Art Libre, http://artlibre.org/.

$17 \mathrm{http} / / /$ www.creativecommons.org/.

18 www.wumingfoundation.com. Sus trabajos se pueden encontrar publicados en la editorial Mondadori.

19 Stallman ya propuso lo mismo en su texto Science Must Push Copyright Aside www.noemalab. com/sections/ideas/ideas_articles/pdf/stallman_2.pdf, pero sin aportar los argumentos y modelos prácticos aquí expuestos. La idea está ya implementada en la Public Library of Science http://www.plos.org que publica según la licencia de crédito (reconocimiento) de Creative Commons.

${ }^{20}$ El caso Williams \& Wilkins contra las bibliotecas públicas de la administración de los Estados Unidos se encuentra ampliamente documentado y comentado en el capítulo 3 de (Goldstein, 1994). La empresa editora reclamaba cobrar los derechos de copyright correspondientes, o una compensación razonable, por el nuevo servicio que prestaban las bibliotecas al fotocopiar artículos completos de algunas de sus revistas científicas.

${ }^{21}$ Un buen ejemplo es el sitio del Proyecto de Filosofía en Español que tiene una página http://www.filosofia.org/derechos.htm destinada a explicar el amparo legal que da la ley a este tipo de actividades educativas no lucrativas. 